\title{
O PROCESSO DE VALORIZAÇÃO DO ESPAÇO URBANO NA CIDADE DE NOVA IGUAÇU E SEUS IMPACTOS NA POPULAÇÃO PERIFÉRICA
}

\author{
THE PROCESS OF VALUATION OF URBAN SPACE IN THE CITY OF NOVA \\ IGUAÇU AND ITS IMPACTS ON THE PERIPHERAL POPULATION
}

\section{Lilian Cristina Gomes Ribeiro ${ }^{1}$}

RESUMO: Esse artigo traz uma breve reflexão e abertura para futuros debates sobre o crescente enobrecimento e estímulo à centralização no município de Nova Iguaçu de que forma ocorreu e por qual motivo esse processo tem sido estimulado, e os impactos que têm sido vivenciados pela a sociedade local, que majoritariamente possui baixo poder aquisitivo considerando que Nova Iguaçu é uma cidade periférica, em relação ao Estado do Rio de Janeiro.

Palavras-Chaves: Enobrecimento. Gentrificação. Nova Iguaçu. Periférica.

ABSTRACT: This article provides a brief reflection and opening for forthcoming debates on the growing ennoblement and stimulus to centralization in the municipality of Nova Iguaçu, how it occurred and why this process has been stimulated and the impacts that have been experienced by the local society, which mostly has low purchasing power considering that Nova Iguaçu is a peripheral city, in relation to the State of Rio de Janeiro.

Keywords: Ennobling. Gentrification. Nova Iguaçu. Peripheral.

\section{INTRODUÇÃO}

A cidade de Nova Iguaçu, localizada na região Metropolitana do Estado do Rio de Janeiro, dentro da sub-região Baixada Fluminense tem passado por um processo de enobrecimento e valorização do espaço urbano, poucos são os estudos acadêmicos voltados para esse tema, grande parte da sociedade local de Nova Iguaçu, carece de conhecimento em relação ao processo de "gentrificação" que o município tem passado algo muito problemático, sabendo que os impactos do mesmo, refletem diretamente na comunidade local. É necessário analisar a forma que ocorreu esse processo de valorização e interesse em estimular a moradia em bairros centrais de Nova Iguaçu.

\footnotetext{
I Graduanda em Turismo pela Universidade Federal Rural do Rio de Janeiro - RJ. Email: liliangomessrb@gmail.com.
} 
No que diz respeito à região da Baixada Fluminense do Estado do Rio de Janeiro, é correto afirmar que existe um estigma de condicionamento à pobreza, de acordo com SANTOS (1987) “Morar na periferia é condenar duas vezes à pobreza. À pobreza gerada pelo modelo econômico, segmentador do mercado de trabalho e das classes sociais, superpõe-se à pobreza gerada pelo modelo territorial.” Esse artigo pretende elaborar de que forma esse processo tem feito crescer esse estigma de pobreza, e a segmentação de classes sociais baixas, e tem como objetivo causar interesse para estudos cada vez mais aprofundados sobre esse tema.

\section{A Valorização do Espaço Urbano em Nova Iguaçu}

Até os anos 1940, segundo a PMNI (2008), o município possuía uma economia baseada na monocultura de exportação. A produção de laranja, que substituiu a lavoura do café, ocupava praticamente toda a área rural do município, onde as fazendas, constituídas por grandes extensões de terras, caracterizavam a divisão e o parcelamento do território. Os primeiros plantios ocorreram nos arredores da cidade, estendendo-se pelas encostas da Serra de Madureira, desde Mesquita até Cabuçu, Ipiranga e Marapicu, e pela grande planície até as proximidades da Serra de Tinguá.

O fim do ciclo da laranja marca o início da transição e a transformação do espaço da

Região da Baixada Fluminense através do fracionamento das terras. Observa-se o processo de ocupação do território de Nova Iguaçu, com desdobramentos que se apresentam com um crescimento desigual entre os distritos formadores do município em questão. Com o propósito de ocupar o espaço dos antigos laranjais, a pressão imobiliária atingiu Nova Iguaçu e foi abrindo caminho para a consolidação da urbanização (OZÓRIO, 2007).

Conforme a Prefeitura Municipal de Nova Iguaçu (2008), na dinâmica de evolução da mancha urbana, a partir de 1950, seguida da década de 1960, o município se fortalece numa estrutura do tipo núcleo-periferia. O núcleo urbano agregaria a maior parte dos recursos disponíveis e a periferia se tornaria cada vez mais carente de serviços públicos adequados. Na capital metropolitana do Rio de Janeiro, além do predomínio de uma distribuição desigual de investimentos estatais, ao longo da década de 1960 a política de remoção de favelas em áreas valorizadas favoreceu a expansão da metrópole carioca em direção à zona oeste da cidade e a outros municípios vizinhos da Região da Baixada Fluminense, como Duque de Caxias e São João do Meriti, sobretudo o município de Nova Iguaçu. 
A partir dos anos 50 ocorreu expressivo crescimento demográfico da cidade de Nova Iguaçu, promovido por uma onda de urbanização que atingiu os limites da cidade, constituindo, assim, uma das fases mais marcantes da expansão física da cidade. Essa urbanização se expandiu horizontalmente em sucessivos loteamentos, desprovidos de infraestrutura e, simultaneamente ocorreu o adensamento e a verticalização de sua área central (OZÓRIO, 2007)

Ocorreram mudanças no município de Nova Iguaçu após as emancipações de importantes distritos como Belford Roxo e Queimados. Em 1990, houve a emancipação de Belford Roxo (segundo menor distrito, porém um dos mais populosos, no qual está localizado a Bayer Indústria Química), seguido por Queimados (no qual está localizado o Polo Industrial que, logicamente, passou a ser administrado pelo novo município). No ano seguinte, em I991, foi a vez de Japeri. Em 1999, Mesquita, distrito de apenas $36 \mathrm{~km}^{2}$, também se emancipou, tendo sua primeira eleição para prefeito no pleito municipal de 20oo. As emancipações causaram um desequilíbrio econômico para o município de Nova Iguaçu, em relação à arrecadação de tributos municipais, com a diminuição da população e, consequentemente, a Bayer em Belford Roxo e o Polo Industrial em Queimados. Segundo a Prefeitura de Nova Iguaçu, o município manteve praticamente o mesmo volume de gastos públicos, causando queda no nível referente à prestação de serviços de infraestrutura urbana.

A maneira como foi sendo estabelecido o crescimento da mancha urbana em Nova Iguaçu foi de forma desordenada, sem planejamento e infraestrutura suficiente para esse crescimento desordenado que se evidenciou pelas desigualdades sociais, visíveis no próprio espaço geográfico na cidade de Nova Iguaçu. A cidade já surgiu com o seu espaço tomado pela forma da desigualdade na sua ocupação socioespacial, reflexo da desigualdade característica da sua ocupação irregular e desordenada.

\section{O Processo de Estímulo a Centralização na Cidade de Nova Iguaçu}

O crescente aumento das distâncias entre o Centro e as áreas residenciais da periferia da cidade, possibilitou a formação de um subcentro comercial, para atender as necessidades da população local.

É possível compreender que a URG Centro se caracteriza por apresentar melhores condições de infraestrutura urbana e de acessibilidade de Nova Iguaçu, sendo uma localização privilegiada e procurada pela elite local. Nesta região, se verifica um padrão de urbanização mais 
consolidado, um melhor estado de conservação das edificações e uma maior presença de vias com traçado regular, com guias e pavimentação. A parte residencial do Centro é ocupada cada vez mais por prédios, mantendo ativa há anos uma indústria imobiliária próspera que produz apartamentos para a classe média e alta. Mas também, o município de Nova Iguaçu, em seu processo histórico de urbanização, é possível observar a ocorrência de uma ocupação desordenada e com muitos contrastes, sendo, de um lado, o Centro da cidade e sua adjacência, com seu comércio, serviços, com equipamentos urbanos e bom nível de urbanização; do outro a periferia com loteamentos precários, implantados de forma fragmentada e/ou desordenada, apresentando moradias/residências construídas em geral por processo de autoconstrução e localizadas, em sua maioria em lotes desprovidos de equipamentos urbanos e de infraestrutura básica.

Devido à forma desordenada que aconteceu a urbanização principalmente no Centro da Cidade, houve a necessidade de criação de um modelo de gestão territorial. O modelo de gestão territorial implementado na cidade de Nova Iguaçu a partir dos anos 9o, estava diretamente atrelado a uma lógica de parceria crescente entre as esferas estadual e municipal do poder público que procurou unir esforços no sentido de viabilizar a reorganização espacial da cidade (COELHO, I996 apud OZÓRIO, 2007).

Conforme a PMNI (2004), no decorrer das décadas de 6o e 7o o Centro do município apresentou-se com poucos sinais de verticalização, no entanto, a região detém cerca de 90\% dos benefícios urbanos da cidade e se caracteriza pela vitalidade do mercado imobiliário, havendo oferta de apartamentos para classe média e alta. Do outro lado, a periferia de Nova Iguaçu, é composta por loteamentos precários implantados de forma fragmentada, em sua grande parte carente de equipamentos de infraestrutura e edificada a partir de casas unifamiliares autoconstruídas.

Em 1999, a prefeitura da cidade deu início ao Plano Estratégico de Nova Iguaçu Participação Cidadã, cujo objetivo central era transformar a Cidade de Nova Iguaçu em um Centro Metropolitano, gerando oportunidades comerciais, de serviços logístico-industriais, dando mais equidade em relação à oferta e distribuição de serviços públicos, melhorando a qualidade da estrutura urbana, tornando-a mais comprometida com a preservação do patrimônio ambiental, histórico e cultural da cidade.

Em 201I, conforme a Lei no 4.092, de 28 de Junho de 20II, fica instituído o Plano Diretor Participativo e o Sistema de Gestão Integrada e Participativa da Cidade de Nova Iguaçu. Segundo 
o artigo 3ํㅡ, o Plano Diretor Participativo - 201 estabeleceram diretrizes e objetivos das políticas de desenvolvimento urbano e da gestão territorial municipal, regulamentando os instrumentos urbanísticos, estabelecendo diretrizes para o parcelamento, o uso e a ocupação do solo e definindo ações, programas, planos, projetos e obras a serem observados até o momento de sua revisão, prevista para ro anos após aprovação desta lei.

De acordo com o Plano Diretor de Nova Iguaçu, o objetivo era estimular as centralidades de Nova Iguaçu, através de parcerias público-privadas, afirmando combater o uso especulativo dos imóveis urbanos, a lei №. 4.092, de 28 de Junho de 201 informa que:

Art. 8 - V. combate ao uso especulativo da terra e imóveis urbanos que resulte na sua subutilização ou não utilização, assegurando o cumprimento da função social da propriedade; (Nova Iguaçu (RJ) 20II Art. 8)

Art. I7- \& 5.ㅇ O Município estimulará parcerias e convênios com associações de moradores, cooperativas habitacionais e a iniciativa privada para a promoção de empreendimentos de HIS; (Nova Iguaçu (RJ) 20II, Art I7)

Art. 20 \& Io. IV. Estimular nas centralidades a exploração de atividades econômicas pelo setor privado, com destaque para os setores de comércio e serviços; V. equipar o espaço urbano com mobiliário adequado, nas principais vias de todos os bairros; VI. fortalecer e potencializar a vocação do Centro de Nova Iguaçu como pólo metropolitano de comércio e serviços; (Nova Iguaçu (RJ) 2011, Art 20).

Art. 95 - O Programa de Centralidades de Nova Iguaçu terá como ponto de partida a rede de centralidades estabelecida no mapa 04, e compreenderá os seguintes conjuntos de ações: (Emenda) I - Fortalecer, ampliar e qualificar as centralidades no território municipal; II - completar e articular a rede de equipamentos sociais; III - Qualificar o espaço público urbano; IV - a ordenação e a qualificação do Centro de Nova Iguaçu. (Nova Iguaçu (RJ) 20II Art 95)

Art. 99 § Io. V - Estimular a moradia no centro. (Nova Iguaçu (RJ) 20II, Art 99)

Faz-se possível, observar que, houve leis de estimulação a moradia no centro, e o aumento da especulação imobiliária é uma consequência natural de tal estímulo, seria necessário, portanto, políticas voltadas para a população habitante nesses centros e suas redondezas. Através da estimulação do poder público em parceria com os agentes produtores do mercado imobiliário grande parte da produção imobiliária se concentra na URG Centro. Trata-se de imóveis destinados a um público de média e alta renda, localizados em uma área restrita (Centro, Kaonze e algumas vias do Bairro da Luz), em locais com melhor infraestrutura e acessibilidade e cujo preço da terra é superior ao de outras partes da cidade, mas havendo significativa distribuição de 
empreendimentos em toda região, pois tais investimentos são oferecidos em forma de edifícios verticais, fazendo com que haja estímulo em diversas áreas, causando uma valorização imobiliária de todo um espaço urbano do Centro.

\section{Os impactos Sociais do processo de Centralização}

Nova Iguaçu está localizada na Região Metropolitana do Rio de Janeiro, sendo um dos maiores centros de comércio e serviços, às margens das mais importantes rodovias e ferrovias do país. Nova Iguaçu está inserida em uma sub-região - a Baixada Fluminense, apresentada há décadas como uma das mais problemáticas do estado, devido aos seus elevados índices de pobreza e violência. Com um território de $519.159 \mathrm{~km}^{2}$ e uma população segundo IBGE (2010) de 796.257 mil habitantes, o município apresenta densidade demográfica de $1.527,60 \mathrm{hab} / \mathrm{km}^{2}$, contra 2.226,43 $\mathrm{hab} / \mathrm{km}^{2}$ em relação ao total da Região Metropolitana. É preciso observar, que a cidade ocupa um espaço de periferia em relação ao Estado do Rio de Janeiro, porém, dentro dessa região periférica, a Baixada Fluminense, o município de Nova Iguaçu exerce uma relação de centralidade. Isso faz com que a população da cidade seja dividida entre pessoas que possuem um nível considerável de poder aquisitivo, enquanto outros vivem em situação clara de pobreza.

Nova Iguaçu é um município de porte médio a grande e é considerado como uma centralidade de caráter regional, um importante polo tanto econômico quanto cultural da região. No entanto, muitos dos problemas de Nova Iguaçu são problemas que dependem de intervenção estadual: concentração de empregos e escolas especializadas no Rio, integração ao sistema rodoviário e ferroviário estadual e federal, transporte intermunicipal, entre outros.

A parte residencial do Centro é ocupada cada vez mais por prédios, mantendo ativa há anos uma indústria imobiliária próspera que produz apartamentos para a classe média e alta. Mas também, o município de Nova Iguaçu, como observado anteriormente, em seu processo histórico de urbanização, se deu através de uma ocupação desordenada e com muitos contrastes, sendo, de um lado, o Centro da cidade e sua adjacência, com seu comércio, serviços, com equipamentos urbanos e bom nível de urbanização; do outro a periferia com loteamentos precários, implantados de forma fragmentada e/ou desordenada, apresentando moradias/residências construídas em geral por processo de autoconstrução e localizadas, em sua maioria em lotes desprovidos de equipamentos urbanos e de infraestrutura básica. Uma vez que URG Centro, conforme a PMNI (2008) representa a região mais antiga da cidade e está incluída na zona urbana consolidada cuja 
tendência é a ocupação pela verticalização, observa-se a concentração de serviços e equipamentos urbanos que se caracteriza com um bom padrão urbanístico, responsável por abrigar cerca de $85 \%$ dos aparelhos urbanos que o município possui e uma alta densidade populacional. $\mathrm{O}$ crescente estímulo público e privado, em conjunto com falha no suporte necessário para evitar que a comunidade local fosse diretamente impactada, faz com que esse processo possa ser observado como gentrificação.

De acordo com Bidou-Zachariasen (2006), vários pesquisadores, na Europa, Estados Unidos e América Latina, estão preocupados com os efeitos que as intervenções de requalificação podem causar nas áreas centrais, pois existem muitos casos em que as famílias moradoras mais pobres foram substituídas por outras de classe média superior, fenômeno que tem sido chamado de gentrificação. Também no Brasil essa preocupação tem sido levantada no meio acadêmico e pelos setores populares ligados a projetos habitacionais ou sociais nas áreas centrais.

Segundo Smith (2007), a gentrificação é intrínseca ao processo de urbanização nas sociedades de economia capitalista. O lucro imobiliário é indissociável de processos de valorização do solo urbano. No entanto, se faz necessário haver uma distinção entre a gentrificação que resulta de processos descoordenados de atuação dos agentes econômicos no setor imobiliário daquela gentrificação que decorre de um processo de reestruturação coordenado, por ações que Harvey (2005, p. 172) chamou de "novo empreendedorismo" e que têm como elemento principal a parceria público-privada, envolvendo a ação combinada de fortes investimentos, realizados com grande intensidade no tempo e sob uma grande parcela da cidade. O caso supracitado de Nova Iguaçu pode ser considerado uma mistura dos dois, pois ocorreu graças a um crescimento desordenado, e logo após uma tentativa de organização desse espaço urbano por meio de políticas públicas.

Mas, qualquer que seja a sua natureza, espontânea e marginal, ou programada e mundial, a gentrificação tem por corolário a saída das classes populares dos centros urbanos. E embora a dimensão classista do processo tenha sido sublinhada pelos primeiros trabalhos que a estudaram (cf, Glass), esta dimensão será eufemizada ou silenciada pelos discursos dos a que programam como política do "renascimento" ou "regeneração" urbana. Tal fato ocorreu na cidade de Nova Iguaçu, o discurso de reorganização e regeneração urbana, foi usado para abafar as problemáticas sociais envolvidas nesse processo.

Smith sublinha todas as ambiguidades do discurso sobre "a volta das populações ao centro", e sobre o "necessário equilíbrio sociológico" constantemente colocado. Trata-se, nem 
mais nem menos, de uma política oficial de gentrificação que, entretanto, não ousa assumir essa designação. A linguagem a regeneração (ou renovação) eufemiza os problemas da polarização social e da exclusão urbana das classes populares.

$\mathrm{O}$ caso de Barcelona nos mostra que a prefeitura rejeita explicitamente o termo “gentrificação", mas suas políticas culturais no centro e a falta de programas de moradias sociais (subsidiada) colaboram para acentuar o atual processo. Embora há trinta anos não fosse mais que um processo marginal, iniciado por alguns atores privados, a gentrificação tornou-se hoje a forma dominante do urbanismo contemporâneo, assim como "a” política urbana das grandes cidades ocidentais, articulando parcerias financeiras público/privadas.

É preciso ter cuidado ao reproduzir tais discursos e ao aplicar as ações listadas no Plano Diretor de Nova Iguaçu, é comum que seja vendida a ideia de que ela (gentrificação) oferece um tipo de espaço urbano que integra ao mesmo tempo trabalho, residência e lazer. Ela representa uma conquista classista da cidade, ela produz também o espaço urbano falsamente democratizado, passível de ser "consumido" parcialmente por outras camadas sociais. Uma utopia, se o discurso não vier acompanhado de ações funcionais e políticas públicas bem aplicadas e fiscalizadas para o desenvolvimento econômico das camadas sociais que vivem em situações precárias.

O interesse por parte dos agentes públicos e privados, fez com que houvesse cada vez mais condomínios de alto nível na cidade de Nova Iguaçu, a criação do Shopping Nova Iguaçu, também aumentou a especulação imobiliária nos bairros adjacentes a ele. A gentrificação deixa de ser, nesse caso, uma anomalia local do mercado imobiliário de uma grande cidade para se desenvolver como um componente residencial específico de uma ampla reformulação econômica, social e política do espaço urbano, e apesar de uma parte dos moradores de Nova Iguaçu possuir condições financeiras para arcar com esse aumento, o espaço se trata, como destacado anteriormente, de uma cidade periférica, com a média salarial de dois salários mínimos, é notório que existe uma parte da população que foi grandemente afetada por essa valorização, pois não possui meios para manter a mesma qualidade de vida, na mesma localidade, com custos tão altos.

Neil Smith questiona, perguntando por que não se propõe também a ida de pobres para os bairros onde habitam apenas os ricos. A diversidade garantiria também os recursos privados para a recuperação e manutenção de edifícios e espaços coletivos. Mas em muitas cidades, como São Paulo, Cidade do México e outras, não há apenas pobres nos centros e poderíamos falar de uma classe média baixa, o que talvez já signifique uma diversidade interessante a manter; De 
qualquer modo, se aceitamos que a diversidade (incluindo as classes médias altas) é desejável, a experiência nos mostra que são necessários instrumentos para garanti-la. Quando se traz pessoas que podem pagar mais (pela moradia, pelo cinema, pelo café...), isso vai provocar o aumento do preço dos imóveis, criando uma situação em que a competição é desigual para moradores e atividades que necessitam aluguéis mais baratos.

A problemática a ser destacada é que esse fenômeno tem feito com que cresça uma espécie de periferia dentro da periferia, uma população periférica crescendo cada vez mais, dentro de um município destacado da sua própria centralidade, no qual a cidade concentra uma pequena parcela da população com alto poder aquisitivo se contrapondo a grande maioria da população do município que não dispõe de tal privilégio. É necessária uma análise voltada para esse fenômeno, levando em consideração que o se o município em si, já é prejudicado por elevados índices de pobreza e violência, devido a negligência do Estado do Rio de Janeiro em relação a essa região, quão mais prejudicada será a sociedade que foi segmentada, por parte do poder público desse mesmo município.

O aumento do custo de vida nos bairros centrais e adjacentes faz com que essa parte da população de Nova Iguaçu, seja cada vez mais colocada de lado, aumentando ainda mais os fatores que fazem a região da Baixada Fluminense ser tão discriminada. Isto não se deve apenas às forças

do mercado. Tal estrutura, também seria função do papel desempenhado pelo Estado no decorrer do tempo, seja através da criação de condições materiais que favoreceram o aparecimento desse modelo dicotômico, seja mediante ao estabelecimento de políticas que, embora objetivando muitas vezes regular conflito entre o capital e o trabalho, sempre acabaram sendo benéficas àquele e em detrimento deste. Para a implementação de políticas públicas tão promissoras quanto as descritas no Plano Diretor de Nova Iguaçu de 2orı, não é possível deixar de lado questões tão importantes como de que forma o próprio poder público deve fazer para minimizar esses impactos, em uma cidade tão bipolarizada, com diversas camadas sociais presentes.

\section{Considerações Finais}

É possível inferir por fim, que o interesse por parte do poder público e privado em relação à valorização do espaço urbano e centralização em Nova Iguaçu, ocorreram com base na forma que foi rápida e desorganizada a urbanização na cidade, devido a isso, se faz necessário a implementação de políticas públicas a fim de tentar reduzir essa desordem, organizar o espaço 
urbano. Harvey (2005) entende que se trata de empreendedorismo, pois "na execução e no projeto, é especulativo, sujeito a todos os obstáculos e riscos associados ao desenvolvimento especulativo." (HARVEY, 2005, p. 173). Porém, muitos fatores precisam ser levados em consideração para a realização dessa organização, a tentativa desenfreada de somente organizar a cidade, sem analisar outros fatores, faz com que a própria comunidade local sofra gravemente. É necessário que haja um equilíbrio e interesse não somente no desenvolvimento econômico, mas também social do município.

É muito improvável que haja a valorização do espaço urbano, sem que haja impactos diretos à sociedade, mas é dever do Estado garantir que esses impactos sejam mínimos, pois já foi observado que em uma cidade como Nova Iguaçu, a população local já sofre com diversas problemáticas, e a negligência em relação às classes sociais menos favorecidas causaria problemas ainda maiores. Portanto, é de suma importância que questionamentos, debates e análises sobre esse assunto sejam cada vez mais levantados, a fim de entender e traçar soluções cabíveis para a realidade local.

\section{Referências Bibliográficas}

BIDOU-ZACARIASEN, Catherine, Cord. De Volta à cidade: dos processos de gentrificação às políticas de "revitalização" dos centros urbanos. Coordenado por Catherine Bidou-Zachariasen com colaboração de Daniel Hiernaux-Nicolas e Hélêne Rivêre d'Are. p. 2I-85 São Paulo : Annablume, 2006.

HARVEY, David. Do Gerenciamento ao Empresariamento: a transformação da administração urbana no capitalismo tardio. Espaço e Debates. Ano XVI, n. 39, 1996. p.48-64. A Justiça Social e a Cidade. São Paulo: Hucitec, 1973.

IBGE, Instituto Brasileiro de Geografia e Estatística. Censo 2oro: Cidades. [Online] Disponível em: 〈https://www.ibge.gov.br/cidades-e-estados/rj/nova-iguacu.html〉, (Acesso em março/2021).

MARTINS, Rogério de Sousa. A Evolução Urbana de Nova Iguaçu: Impactos nos corpos hídricos focando o problema das inundações no centro da cidade. - Rio de Janeiro, 2016. 
MESENTIER, Leonardo Marques \& MOREIRA, Clarissa da Costa. PRODUÇÃO DA PAISAGEM E GRANDES PROJETOS DE INTERVENÇÃO URBANA: O CASO DO PORTO MARAVILHA NO RIO DE JANEIRO OLÍMPICO. Disponível em <DOI: http://dx.doi.org/10.22296/2317-1529.2014vi6nip35?> (Acesso em março/2021)

Nova Iguaçu. Atos Oficiais. Nova Iguaçu, RJ, 20Ir.

Nova Iguaçu. Prefeitura da Cidade de Nova Iguaçu. Plano Diretor Participativo, lei No. 4.092, de 28 de Junho de 20Ir. Nova Iguaçu, RJ, 20II. Disponível em: <https://www.cmni.rj.gov.br/site/legislacao-municipal/plano-diretor/plano-diretorrepublicacao-em-06-06-12-2-31.pdf>. (Acesso em março/2021).

Nova Iguaçu da cidade que temos à cidade que queremos. Diagnóstico da cidade de Nova Iguaçu e proposta do Plano Diretor Participativo; Nova Iguaçu: 2008.

Plano Diretor Participativo, Nova Iguaçu, Rio de Janeiro: 2010.

, Plano Estratégico, Nova Iguaçu, Rio de Janeiro: 2000

OZÓRIO, E. C.. O processo de (re) produção do espaço urbano na cidade de Nova Iguaçu-RJ:

(1990-2007). Dissertação (Mestrado em Planejamento Urbano e Regional). UFRJ, Rio de Janeiro, 2007. / Elaine Cristina Ozório - 2007.

SANTOS, Milton. A Urbanização Brasileira. São Paulo. Hucitec, 1993. Espaço e Método. São Paulo, Nobel, 1985.O espaço do cidadão. São Paulo: Nobel, 1987.

SMITH, N. (1979) Toward a Theory of Gentrification: A Back to the City Movement By Capital Not People. Journal of the American Planning Association, n. 45, p. 538-48. 